\title{
Media: Shaping the Literature of the Age
}

\author{
Mita Bandyopadhyay and Arindam Modak \\ Department of Humanities and Social Sciences, \\ NIT, Durgapur, West Bengal, India
}

\section{ABSTRACT}

Literature, generally considered a form of linguistic art, has constantly been reshaping and reformulating itself under the impact of socio-economic structure which at its base is presently controlled by technological forces overpowering the contemporary society. The influence of technology in shaping the literary spirt of the age can be documented from the way technological development has correspondingly brought a shift not only in the modes of production of literature and its consumption by the masses, but its very content and structure, which too has undergone a remarkable modification. The medium of expression, which at the very initiation of human civilization used to be cave paintings, clay tablets, papyrus, oral recitation, block printing, slowly got replaced and took a new form and identity with the invention of print media, and now with digital media in its full flair, literature has again reconfigured its form and structure into a distinct form of expression, which has again questioned the valid precepts of literature. These changes in the modes of production and consumption of literature, from the physical to the mechanical to the digital, has time and again revived and renewed the essence of literature. Earlier it was the printing press in the fifteenth century and now the user generated content of Web 2.0 of the twenty- first century that has set the tone of literature in a new direction. Through this paper an attempt has been taken to study these changes in the very expression of literature as defined and shaped by media; especially, the digital media which has set the tone of literature in an altogether different mode.

\section{KEY WORDS: MEDIA, LITERATURE, INFLUENCE, CHANGE.}

\section{INTRODUCTION}

"The electric technology is within the gates, and we are numb, deaf, blind, and mute about its encounter with the Gutenberg technology, on and through which the American way of life was formed. It is, however, no time to suggest strategies when the threat has not even been acknowledged to exist. I am in the position of Louis Pasteur telling doctors that their greatest enemy was quite invisible, and quite unrecognized by them. Our conventional response to all that it is how they are used that counts, is the numb stance of the technological idiot. For the 'content' of a medium is like the juicy piece of meat carried by the burglar to distract the watchdog of the mind" (McLuhan).

Biosc Biotech Res Comm P-ISSN: 0974-6455 E-ISSN: 2321-4007
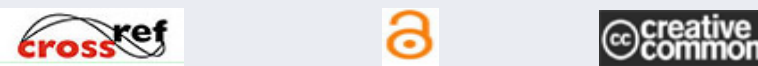

Identifiers and Pagination

Article Information

Year: 2021 Vol: 14 No (8) Special Issue

Pages: 81-85

Received: $20^{\text {th }}$ June 2021

This is an open access article under Creative

Commons License Attribn 4.0 Intl (CC-BY).

DOI: $h t t p: / / d x$.doi.org/10.21786/bbrc/14.8.20
The above quotation by McLuhan clearly states the under esteemed function of media, which has mostly gone unnoticed over centuries, until recently when the birth of digital media has brought about significant shifts in the ways of expression of human thoughts and ideas. Over decades scholars and critics have contested over the definition of literature, evaluating it mainly through its content and structure, being totally unaware of the underlying forces driving the socio-economic structure, the change of which makes a paradigm shift in the literature also. While initially agriculture was the base, now it is the digital technology on which is the superstructure of digital literature.

Through this paper an attempt has been taken to study the influence of media in different time periods, the usage of which has defined the literary creation of the age, yet, its impact has hardly been taken into consideration. Special reference has been drawn to the digital media and the way it has impacted and given a new form to the content and structure of literature. The focus of the article mainly remains centred on the study of the influence of media on the literature of different ages, from the pre-historical period to the modern technocentric digital world. This shifting paradigm, from the 
analogue to the digital, has confronted scholar, critics, and professors with the precepts of literature, which all the while had been loosely accepted and appreciated as a linguistic art form.

Defining Literature: The word literature has several attributes to its meaning, but primarily it has been accepted to signify "writing formed with letters" because of its etymological affiliation to the Latin word, litaritura/ litteratura. In an attempt to concretise literature, Terry Eagleton in his essay, "What is Literature?" discussed, "Perhaps literature is definable not according to whether it is fictional or 'imaginative', but because it uses language in peculiar ways. On this theory, literature is a kind of writing which in the words of the Russian critic Roman Jacobson represents an organized violence committed on ordinary speech"' But then, he again contradicts this prevalent notion by arguing later in the same essay, “There is no 'essence' of literature whatsoever.

Any bit of writing may be read 'non-pragmatically', if that is what reading a text as literature means, just as any writing may be read 'poetically'. If I pore over the railway timetable not to discover a train connection but to stimulate in myself general reflections on the speed and complexity of modern existence, then I might be said to be reading it as literature" (Eagleton). Therefore what comes out of the discussion is that forming any concrete definition of literature is difficult and this has become more complicated with the advent of the digitalization, which has ushered a remarkable shift in the way literature is being created, proliferated and consumed by masses; it being not only limited to words on the screen, but use of images, sound and movement, attributes which were unconceived within the body of literature hitherto.

Media And Literature - A Review: Since the advent of the phonetic alphabet, approximately five thousand years ago, human beings have become attuned to understand and accept literature broadly through the alphabetic representation of the written text, which saw the mass production and distribution after the invention of the print media. Though Terry Eagleton in his two editions of Literary Theory: An Introduction have undermined any strict definition of literature, still scholars, critics and teachers of literature have taken into consideration literature as something produced in the linguistic medium and that it is generally a work of the prose, poetry, drama, novel, short story, and essay, possessing certain technical and narrative skills, aesthetic, cognitive and interpretative value and is possibly the work of an esteemed writer. Still, setting up any fixed premise for literature can never be possible because literature is never unidimensional; it too is growing and expanding, its ways of expression being swayed by the forces of changing technology, which at present forms the base of economic production of the society.

Communication or the expression of ideas originated as pictorial representation called the pictograms; its medium of expression being the walls of the caves, stones or clay tablets. It was a form of expression practiced much before the advent of speech and writing. Early evidence of writing can be tracked back to the Egyptian hieroglyphics on the clay tablets, stone carvings or the papyrus made from the bark of the trees; even at this stage expression was mainly symbolical representation. Within the period of several centuries, when the formation of the script was taking its concrete shape, it was the oral medium of literary expression that flourished in its full bloom. Both Finnegan and Meyer in their respective works have insisted on and championed the oral tradition as a prevalent form of literature across the world in the era before the written form of expression had become common. Even after writing had been in vogue, it was in the possession of the royal families and with the people of the religious order who maintained records, or else created texts that bore a classical taste. As the written form thrived within the highest rung of the social ladder, its content too depicted the people and life style of that stratum of the society. It was centuries after the invention of paper in China and later its usage in different continents that the medium of writing as mode of expression as well as communication started to percolate a little deeper among masses.

However, it should be born in mind that before the invention of the printing press literature was not for everyone, it was a form of expression solely in the possession of the elite section of the society, and the people of the religious order whose livelihood resonated the understanding of the works of the scriptures. Technological advancement, that is, the invention of paper, the ink, and above all the print media gave a spurt and vigour in the spread of literature and made it available to the masses. The greatest effect of the printing press can be estimated from the spread of Renaissance spirit from Italy to almost the entire continent, affecting religion, politics and the human life and living forever. The effect of Renaissance, which was carried off to the far flung areas, marked a visible modification in the content and form of the contemporary literature and language.

Literature which had centred on the lives of the kings and the royals for centuries like Plutarch's Life of Noble Greeks and Romans written in the 2 nd century AD saw a shift with Chaucer's Canterbury Tales, wherein characters like the Wife of the Bath, the host of the Tabard Inn, the ploughman, the clerk and several others who were not in the class of the nobility, but reflected the society at large, did secure a place in the work of Chaucer; even the language used showed a marked difference from its earlier version. It was the work of Chaucer and his renaissance spirit under the influence of Dante and Boccaccio that brought into focus the theme of contemporary society into English Literature, and the use of vernacular language in the written texts.

The technical advancement made in the form of print media changed the course of literature forever. The mass production of literary pieces not only moved it out of the aristocratic feudal gentry and the religious order, but lead to the formulation of newer forms of literature in the form of essays by Francis Bacon, Diary by Samuel 
Pepys, and journalistic pamphlets by Defoe, Addison, and Steele, bringing into parlance issues of the contemporary society in lucid and simple language for the common people. This proliferation of literature among people of different class and gender led to the creation of the new literary genre, the novel. It even drew the women into the realms of literature, both as producers and consumers of the latest linguistic art form. So, the influence of media in shaping literature and thereafter the culture of the age becomes clearly discernible.

The Gutenberg printing press of 1439 brought about drastic change in the means of production of literature, which in turn affected the contemporary ideology of the masses; though, print using the block was in practice through centuries. Plethora of printed material flooded the market, making books cheap and easily available. Such availability got more people educated and kept them informed about the worldly affairs, shaping the literary output of the age. Not only did printing give rise to the mass production of literary material, but it also shaped human thoughts by exposing them to new ideas of science, politics as well as exploration of new land; all of which went on to mould the literature with new ideas. This effect of technology, that is, media on literature and through literature the changing cultural ethos has effectively been explained by McLuhan:

"What we are considering here, however, are the psychic and social consequences of the designs or patterns as they amplify or accelerate existing processes. For the 'message' of any medium or technology is the change of scale or pace or pattern that it introduces into human affairs. The railway did not introduce movement or transportation or wheel or road into human society, but it accelerated and enlarged the scale of previous human functions, creating totally new kinds of cities and new kinds of work and leisure. This happened whether the railway functioned in a tropical or a northern environment, and is quite independent of the freight or content of the railway medium. The airplane, on the other hand, by accelerating the rate of transportation, tends to dissolve the railway form of city, politics, and association, quite independently of what the airplane is used for"(McLuhan). In this context according to McLuhan what the media did was not only did it accelerate the entire process of literary production, but it gave rise to new forms, ideas and ideologies. The dawn of the new millennium replaced the mechanical mode of production with the digital mode and that has made all the difference.

The Era Of Digital Media: The present era of digital culture emerged with the development of computers in the 1960s. But it was only with the invention of the user generated content of Web 2.0 that unlocked the flood gates of opportunities for the readers, in the sense, the role of the readers for the first time got elevated from being passive to active and this input of the reader's participation was something new to the world of literature. The combined effect of the World Wide Web and the digital technology together with the handy gadgets such as the smartphones, laptops, tablets have led to the rise of social media, Facebook, Twitter, Youtube, Instagram which have altogether revolutionised the way communication of information as well as exchange of ideas have been shaping across the globe since the last decade.

The impact of digital technology has created what is known as digital literature, a new form which has been defined as "a construction whose literary aesthetics emerge from computation", " a work that could only exist in the space for which it was developed/written/ coded-the digital space"(Heckman, 0'Sullivan). Katherine Hayles in her book, Electronic Literature: What is it? (2007) explained more specifically this new form of literature, as a form that excludes print literature that has been digitized; this new form of literature being born on digital media does not allow to be printed on paper, but is meant to be read on a computers. This new form of literature is shaping itself through numerous ways of expression, the guidelines of which have been set by ELO (Electronic Literature Organization). According to ELO, digital literature is created on e-books comprising of hypertext, conversational characters, collaborative efforts of the readers and writers, poetry using animated graphics, novels created using a combination of the text, images, audio and video, or else novels created through the use of emails, sms and blogs.

Jason Nelson's novel, Nine Billion Branches, a work of digital literature which won the inaugural award for digital literature at Queensland Literary Award, is an ideal example of the digital literature. The non-linear structure of story-telling is actually very new and had been problematic for the jury to come to any particular decision; a fact that has been brought to focus by Simon Groth, one if the jury in the award ceremony in his article "Still Defining Digital Literature":

"The first consideration for me is examining how text is used as an integral part of the narrative. Video, animation, graphics, and audio can all of course be combined variously to create inventive narratives, but an entry where text does not form a significant part of the storytelling. For me this would fall too far outside the scope of a literary award; even works that are clearly worthy in this regard bring challenges for judges. How does one judge, for example, non-linear poetry against remix works against linear prose augmented by multimedia elements? Subjectivity does come into this, but the task requires judges to consider the purpose of narrative. For me that means thinking about the quality of the connection between writer and reader and the clarity of the communication between" (Groth).

Digital technology has facilitated the dissemination of literature by blurring the role of the publisher. While initially an author needed a publisher to get the work published, the work can now be published independently on the Amazon Kindle, added to which the author gets an estimate of views of the readers through the social networking cites. A significant example in the field 
of digital literature is noted through the work of E.L. Jame's Fifty Shades of Grey (2011) and its corresponding sequels, Fifty Shades Darker (2011), Fifty Shades Freed (2012) Jame is an author who was never into serious writing before 2009, and it was in response to Stephenie Meyer's Twilight that she started to write and it shot her to instant fame taking her to the top of the list of the highest paid authors in the Forbes magazine. The trilogy has been negatively criticized by distinguished authors, columnist and reviewers all though; Libby Hill of Los Angel's Times commented, "The books were critically savaged hot messes that sold over 100 million copies for the sex." But the popular demand fetched her the award of "Popular Fiction" and "Book of the Year Award" in the year 2012 (Flood).

The social media cites, the blogs, the fan fiction provide an interactive space to anyone who can write and express themselves through poems, anecdotes, travelogues, articles, reviews, meditative essays, novels, and get instant reviews from the readers and then proceed further. The art of writing is no more within the preview of a handful of people, it is now within the command of both the writer and reader to formulate and give a new form and structure to the story material. Authors like Miranda Dickinson whose book, Take A Look At Me Now (2013), and Jennifer Egan whose story Black Box (2012), used suggestions from Twitter followers to make significant developments on every details, from plot to character, as required. Julie Powell, one of the earliest examples of a blogger turned into an author became famous through her blog which later got published in the book form, Julie and Julia: 365 Days, 524 Recipes (2005), finally moving into the film production by the name Julie and Julia.

The Instagram is another social media cite where the writers post their creative material and receive instant views and comments from the readers. These social media cites have led to the creation of the new generation poets like Atticus, Rupi Kaur, Mustafa The Poet, Adrian Hendryx, Nikita Gill, Samantha Jayne, Tyler Knott Gregson, Lang Leav. These insta-poets as they called have seen a considerable rise in the sale of poetry which had gone down over the decades. Rupi Kaur's first collection of poems, Milk and Honey became the New York bestseller selling over 15000 copies. "More than a million poetry books were sold in the last year, the highest number on record, as the popularity of social media sensations such as Rupi Kaur continues to reinvigorate the art form. Sales are up 13\%, to $£ 10.5 \mathrm{~m}$, according to figures from Nielsen Book Research” (Walker, R).

The digital technology, which outwardly appears to be a mere shift from the analogue to the digital world, is not a meagre change; it has no matter brought literature within the easy reach of one and all, giving rise to new challenges and possibilities. The new media, that is, the digital media has allowed the proliferation of literature into different forms bringing into use the hypertext, network fiction, interactive fiction, flash poems, locative narrative, code work such that it becomes difficult to formulate a unified linear interpretation of the text. The use of different forms of techniques in creating a piece of literature has not only disrupted its linearity, but has made it complicated "Indeed, this unsureness and ambiguity have resulted in many students generally beginning to turned off by their initial attempts to enjoy digital literatures - dismissing them as too difficult to understand or seeming to lack any discernible meaning" (Jewitt).

\section{CONCLUSION}

Very often in the pursuit of defining literature, the role of media gets effaced. Critics, scholars and professors in the past century have evaded the influence of media while trying to define literature in print; may be because the role of the print media in developing literature has not been so complicated, though it too introduced certain modification. But digital technology has altogether changed the perspective of media, bringing it from the margin to the centre of the literary world. Digital media has changed the basic form of literature making it non-linear, posing question to its form and content, thus, drawing into focus the impact of media in shaping literature. It has shown the multiple ways in which media can modify a literature by introducing sound, image, movement and above all the instant reviews of the readers, something which captures the spirit of the contemporary, and then, boomerangs through literature, every time, etching out a new form. "Electronic media are not simply changing the way we tell stories: they are changing the very nature of story, of what we understand (or do not understand) to be narratives" (Unsworth). Thus, media which hitherto had been considered passive, without having noticeable impact on the content or the form of the text, has all of a sudden become all powerful and pervasive only because it has shifted the paradigms of literature, affecting not only its content, but its very form and structure. and also the place enjoyed by the audience

\section{REFERENCES}

Eagleton,Terry. (2003) Literary Theory: An Introduction. The University of Minnesota Press, II 1-14.

Finnegan, Ruth. (1947) "How Oral Is Oral Literature?". Bulletin of the School of Oriental and African Studies, 37 (1): pp.52-64. doi:10.1017/s0041977x00094842. JSTOR 614104

Flood, Alison. (2012) "EL James comes out on top at National Book awards". The Guardian, London, Dec. 5,. https://www.theguardian.com/books/2012/dec/05/ el-james-national-books-award

Groth, Simon. (2018) “Still Defining Digital Literature”. The Writing Platform, May 20. http://thewritingplatform. com/2018/05/still-defining-digital-literature/

Hayles, Katherine. (2007) Electronic Literature: What Is It? In Electronic Literature Organization (publications). http://eliterature.org/pad/elp.html

Heckman, Davin; O’Sullivan, James. (2018) "Electronic Literature: Contexts and Poetics". Literary Studies in 
the Digital Age: An Evolving Anthology.

Hill, Libby . (2016) "First 'Fifty Shades Darker' trailer filled with lots of plot, little kissing". Los Angeles Times, Sept 13. https://www.latimes.com/entertainment/ movies/la-et-mn-fifty-shades-darker-trailer-20160913snap-story.html

Jewitt, C (2005) "Multimodality, 'reading', and 'writing' for the 21st century". Discourse: Studies in the Cultural Politics of Education, vol. 26, no. 3 . pp. 315-31

Mcluhan,Marshall.. "The Medium is the Message". Understanding Media: The Extensions of Man. https:// web.mit.edu/allanmc/www/mcluhan.mediummessage. pdf
Meyer, Jim . (1997) "What is Literature? A Definition Based on Prototypes". Work Papers of the Summer Institute of Linguistics, University of North Dakota Session, 41 (1).

Unsworth, Len. Multiliteracies, (2008) E-Literature and English Teaching. Language and Education, Vol 22, no.1, pp. 62-75.

Walker, Rob (2017 ) “Now it's the coolest thing': rise of Rupi Kaur boosts up poetry sales”. The Guardian. . 7th October. https://www.theguardian.com/books/2017/ oct/07/now-its-the-coolest-thing-rise-of-rupi-kaurhelps-boost-poetry-sales 